Article

\title{
Estimating the Optimal Velocity Measurement Time in Rivers' Flow Measurements: An Uncertainty Approach
}

\author{
Robert Clasing ${ }^{1}$ and Enrique Muñoz ${ }^{1,2, *}$ \\ 1 Department of Civil Engineering, Universidad Católica de la Santísima Concepción, \\ Alonso de Ribera 2850 Concepción, Chile; rjclasing@ing.ucsc.cl \\ 2 Centro de Investigación en Biodiversidad y Ambientes Sustentables (CIBAS), Universidad Católica \\ de la Santísima Concepción, Alonso de Ribera 2850 Concepción, Chile \\ * Correspondence: emunozo@ucsc.cl; Tel.: +56-99-609-1945
}

Received: 4 July 2018; Accepted: 27 July 2018; Published: 31 July 2018

\begin{abstract}
The gauging process can be very extensive and time-consuming due to the procedures involved. Since velocity measurement time (VMT) is one of the main variables that would allow gauging times to be reduced, this study seeks to determine the optimal point VMT and, thereby, reduce the overall gauging time. An uncertainty approach based on the USGS area-velocity method and the GLUE methodology applied to eight gauging samples taken in shallow rivers located in South-central Chile was used. The average point velocity was calculated as the average of 1 to 70 randomly selected instant velocity samples (taken every one second). The time at which the uncertainty bands reached a stability criterion (according to both width and slope stability) was considered to be the optimum VMT since the variations were negligible and it does not further contribute to a less uncertain solution. Based on the results, it is concluded that the optimum point VMT is $17 \mathrm{~s}$. Therefore, a point velocity measurement of $20 \mathrm{~s}$ is recommended as the optimal time for gauging in shallow rivers.
\end{abstract}

Keywords: gauging; GLUE; uncertainty analysis

\section{Introduction}

Hydrological studies are based on a set of hydrometric and meteorological data that must be measured directly in the field with a precision suitable for the intended purposes [1]. One type of such data consists of flow records, which prove indispensable since effective management of water resources requires precise flow measurements [2].

Streamflow magnitude is determined directly by flow measurements. Among the various flow measurement methods, the most commonly used in both shallow and deep rivers is the area-velocity method since it is a precise method that is simple to carry out in the field [3]. Streamflow is calculated as the product of area and velocity. The measurement is made by subdividing the cross-section of the flow into segments (known as subsections, verticals, or partial areas) through the measurement of depth, width, and velocity within each vertical. The total streamflow is the sum of the products of the partial areas of the cross-section and their respective average velocities [4].

USGS [5] recommendations indicate that the spacing of the verticals should provide between 25 and 30 subsections. They should be spaced such that no subsection has more than $10 \%$ of the total streamflow. The ideal measurement is one in which a subsection has at most $5 \%$ of the total streamflow, but this is rarely achieved with 25 subsections [5].

According to the USGS [4], velocity observations in each vertical must consist of measurements of at least $40 \mathrm{~s}$ and, in the case of mechanical current-meters, they must be between 40 and $70 \mathrm{~s}$. 
The measurement points at each vertical vary by depth (Table 1) with the following methods used for wading measurements: (i) One-point method: a velocity measurement must be made at $0.6 \mathrm{H}$ with $\mathrm{H}$ representing depth, which is measured from the water surface to the river bottom. In this case, the measured velocity represents the average velocity of the water column and is assumed to be representative of the subsection, (ii) Two-point method: observations are made in the vertical at 0.2 and $0.8 \mathrm{H}$ and the average velocity in the vertical is determined by calculating the arithmetic mean. This method applies to depths greater than $0.46 \mathrm{~m}$ and, according to the USGS [4], to current-meters such as Pygmy or ADV (Acoustic Doppler Velocimeter). In addition, if the velocity at $0.8 \mathrm{H}$ is greater than the velocity at $0.2 \mathrm{H}$, or if the velocity at $0.2 \mathrm{H}$ is double the velocity at $0.8 \mathrm{H}$, the measures will be deemed abnormally distributed velocities and the three-point method will be recommended [4]. (iii) Three-point method: this method applies when velocity is seriously affected by friction or turbulence produced by the streambed or an obstruction in the stream. The average velocity of the subsection is calculated, according to the equation indicated in Table 1. Velocities must be measured at $0.2,0.6$, and $0.8 \mathrm{H}$ (from the water surface). This method only applies when river or canal depths are greater than $0.46 \mathrm{~m} \mathrm{[4].}$

Table 1. Average velocity at various depths for wading measurements [5].

\begin{tabular}{cccc}
\hline $\begin{array}{c}\text { Number of } \\
\text { Measurements }\end{array}$ & Depth $(\mathbf{m})$ & $\begin{array}{c}\text { Points Measured from } \\
\text { the Water Surface }\end{array}$ & $\begin{array}{c}\text { Mean Velocity } \\
\text { Calculation }\end{array}$ \\
\hline 1 & $0.09-0.46$ & 0.6 & $\mathrm{~V} 0.6$ \\
2 & over 0.46 & 0.2 and 0.8 & $0.5(\mathrm{~V} 0.2+\mathrm{V} 0.8)$ \\
3 & over 0.46 & $0.2,0.6$ and 0.8 & $0.25(\mathrm{~V} 0.2+2 \mathrm{~V} 0.6+\mathrm{V} 0.8)$ \\
\hline
\end{tabular}

Depending on the regulations for carrying out flow measurements and point velocity measurement time (VMT), developing flow measurements may be a very extensive task. To simplify it without sacrificing precision or the quality of the results, electronic devices have been developed that simplify the data acquisition process and improve data precision, but measurement times and field resource expenses can still be optimized. Therefore, optimization of the different stages of the flow measurement process is aimed at reducing both the resources needed and the risk associated with measurement.

Techniques to quantify uncertainty in streamflow data have made up an increasingly important area in hydrological research [6] since data reliability depends on uncertainty in the data and the calculation method [7]. Moreover, flow data affects subsequent water resources management. Therefore, inadequate attention to aspects such as data quality and streamflow record uncertainty when making decisions could lead to unsatisfactory results [8].

A few studies aimed at improving streamflow data quality and uncertainty while optimizing the measurement process have been carried out. For example, Coxon et al. [9] studied the streamflow uncertainty at gauging stations to provide a streamflow benchmark in England and Wales. Saldías [10] automated data acquisition and processing to improve efficiency in these areas. Helmbrecht et al. [11] and Fernández et al. [3] studied streamflow uncertainty based on the ISO standard 748 [12]. However, the point VMT for flow measurements have not yet been reduced or optimized.

Beven and Binley [13] developed a methodology for the estimation of uncertainty associated with a hydrological model. Its use was demonstrated by an application to a runoff dataset from the Gwy experimental catchment of the Institute of Hydrology in Plynlimon, mid-Wales. This method, called the Generalized Likelihood Uncertainty Estimation (GLUE), represents an extension of the generalized sensitivity analysis published by Hornberger and Spear [14] and Spear et al. [15]. It involves randomly choosing several model parameter sets with the possibility of carrying out various simulations that can represent reality. The objective of the GLUE methodology is to produce a set of values that adequately reflect the uncertainty resulting from the modeling process and that reproduce the observed behavior within a range of feasible results [16]. GLUE has been used in the calibration and analysis of the predictive capacity of models of solute transport in a river [17] in the analysis of parameter 
uncertainty in hydrological and sediment modeling [18] and in the study of hydrological model behavior [19] among other areas. Therefore, it appears to be adequate for use in this study to calculate the uncertainty associated with flow measurements for different point VMTs and, thereby, define an optimal measurement time.

This study aims to determine the optimal point VMT for flow measurements in order to reduce the total time needed for the process. To this end, a stability criterion of variation of the uncertainty bands (estimated using GLUE) is used. In addition, since the objective of the study is to estimate the optimal time for point velocity measurements, a single, broad method for the flow measurement (i.e., the USGS, 2010 area-velocity method) method is used.

\section{Study Area}

Eight gauging points located in South-central Chile were selected to carry out the measurement and analyses. These points were selected in order to cover several different morphological and hydraulic characteristics (i.e., width, depth, and velocity among others). Figure 1 shows the locations of the flow measurement points while Figure 2 summarizes the geometric and velocity characteristics of the measured sections. Figure 2 shows a range of widths of $3.6 \mathrm{~m}$ to $47.8 \mathrm{~m}$, maximum depths of $0.24 \mathrm{~m}$ to $1.17 \mathrm{~m}$ and average velocities from $0.012 \mathrm{~m} / \mathrm{s}$ to $0.88 \mathrm{~m} / \mathrm{s}$.

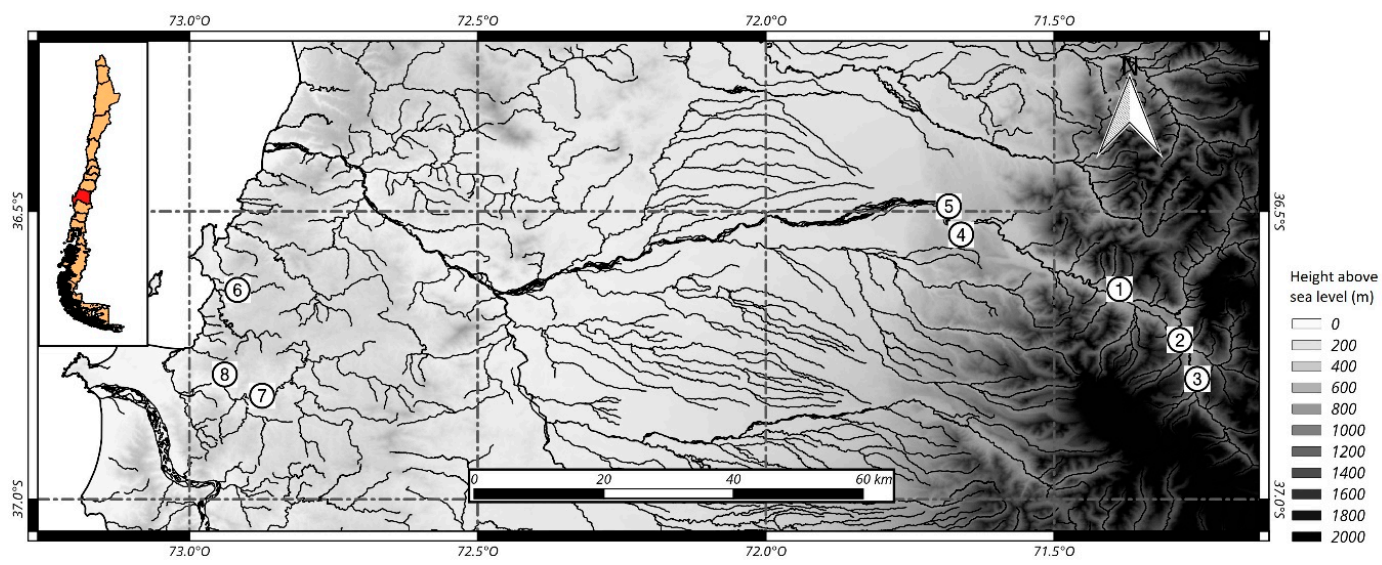

Figure 1. Study area and locations of flow measurements carried out.

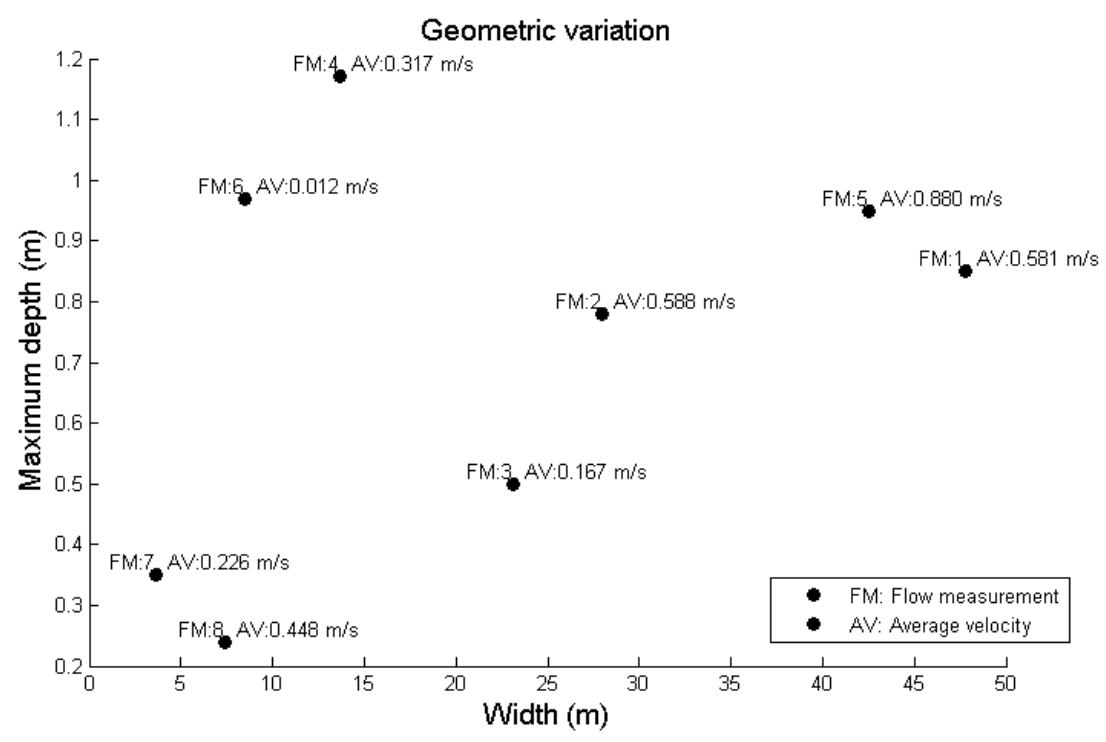

Figure 2. Geometric and flow characterization of the gauged sections. 


\section{Methods}

For a flow measurement calculation, the geometric characteristics of the river section are required and the velocity must be measured at different depths. The velocity that is used for the calculation corresponds to the arithmetic mean of the time series of velocities measured at each point. To calculate uncertainty following GLUE methodology, it was assumed that each instantaneous velocity measurement (measurements are carried every one second) corresponds to a random representative value at each recording point. Subsequently, the area-velocity method is used to calculate the total streamflow of the flow measurement. Simulation of this process at different measurement times gives different streamflow results. To obtain the uncertainty that adequately reflects the flow measurement, the process is carried out repeatedly by generating all the potential results and, therefore, uncertainty bands.

To determine the total streamflow of a river cross-section, the area-velocity method was used as a basis for this study. In this method, the streamflow of a subsection is the product of the area and its average velocity. At the same time, the total streamflow is the sum of the stream-flows of all of the subsections. The present study aims to determine the optimum average VMT for a flow measurement using the point measurement method [5], which is an established and widely used method.

The GLUE methodology rejects the notion of only one optimal solution and adopts the concept of the model, parameter, and variable equifinality [13]. Equifinality stems from the imperfect knowledge of the system under consideration. Therefore, different sets of models, parameters, and/or variables have some probability of certainty to correctly represent a system. The GLUE methodology aims to find possible sets of models, parameters, and/or variables that represent an observed natural process in an equivalent manner. Therefore, when there are different equivalent representations of a system, the uncertainty of the representation is obtained.

Considering that the average VMT is one of the main variables that would allow flow measurement times to be reduced, this study focuses on determining the optimum measurement time at each point and, thereby, reducing the total time needed for a flow measurement. To this end, the methodology of this study considers the velocity at each flow measurement point as a set of independent variables that compose a random sample of velocity.

In the flow calculation and uncertainty estimation procedure, average velocities at each flow measurement point for different measurement times from 1 to $70 \mathrm{~s}$ (or instant measurements) were calculated. For example, one random value was extracted from the velocity sample when the measurement time was $1 \mathrm{~s}$. Likewise, for a measurement time of $2 \mathrm{~s}$, two random values were used to calculate the average velocity until $70 \mathrm{~s}$ of average velocity measurements were completed at each gauging point. Subsequently, the mean velocity for each vertical was calculated according to the USGS [5] criteria described in Table 1 and the total streamflow of each flow measurement was calculated using the area-velocity method. The random extraction of velocity values was carried out with a uniform probability distribution.

To create the uncertainty surface or region, the Monte Carlo method was used, which consists of carrying out " $\mathrm{n}$ " experiments with randomly chosen variables. This results in a set of possible results, which make up the uncertainty bands. In this study, 50,000 streamflow simulations at different VMTs for each flow measurement section were carried out. In the subsequent analysis of them, the extremes of the possible results ( $5 \%$ highest and lowest) were discarded and the remaining results were defined as the uncertainty bands.

Field records were obtained according to the recommendations of the USGS [4]. A flow measurement selection criterion consisting of shallow rivers with depths of less than $1.6 \mathrm{~m}$ was established. Eight flow measurements were carried out with 26 verticals per gauging point. The geometry of each section and associated vertical was recorded. Then the instantaneous velocity for each second of measurement was recorded over a total time of $120 \mathrm{~s}$. Therefore, a sample with 120 random instantaneous velocity records was obtained for each velocity measurement point, which 
allowed for the sample size to be considered wide, representative, and sufficient for obtaining random values for use with the GLUE method.

Figure 3 shows a scheme of the results obtained for the flow measurement made at Gauge 1. Figure 3 a shows a streamflow simulation with different times for the calculation of average velocity per subsection. Figure $3 \mathrm{~b}$ shows 50,000 simulations of the same streamflow for different measurement times and Figure $3 c$ shows the flow measurement uncertainty bands and their average, which is represented by the solid black line.
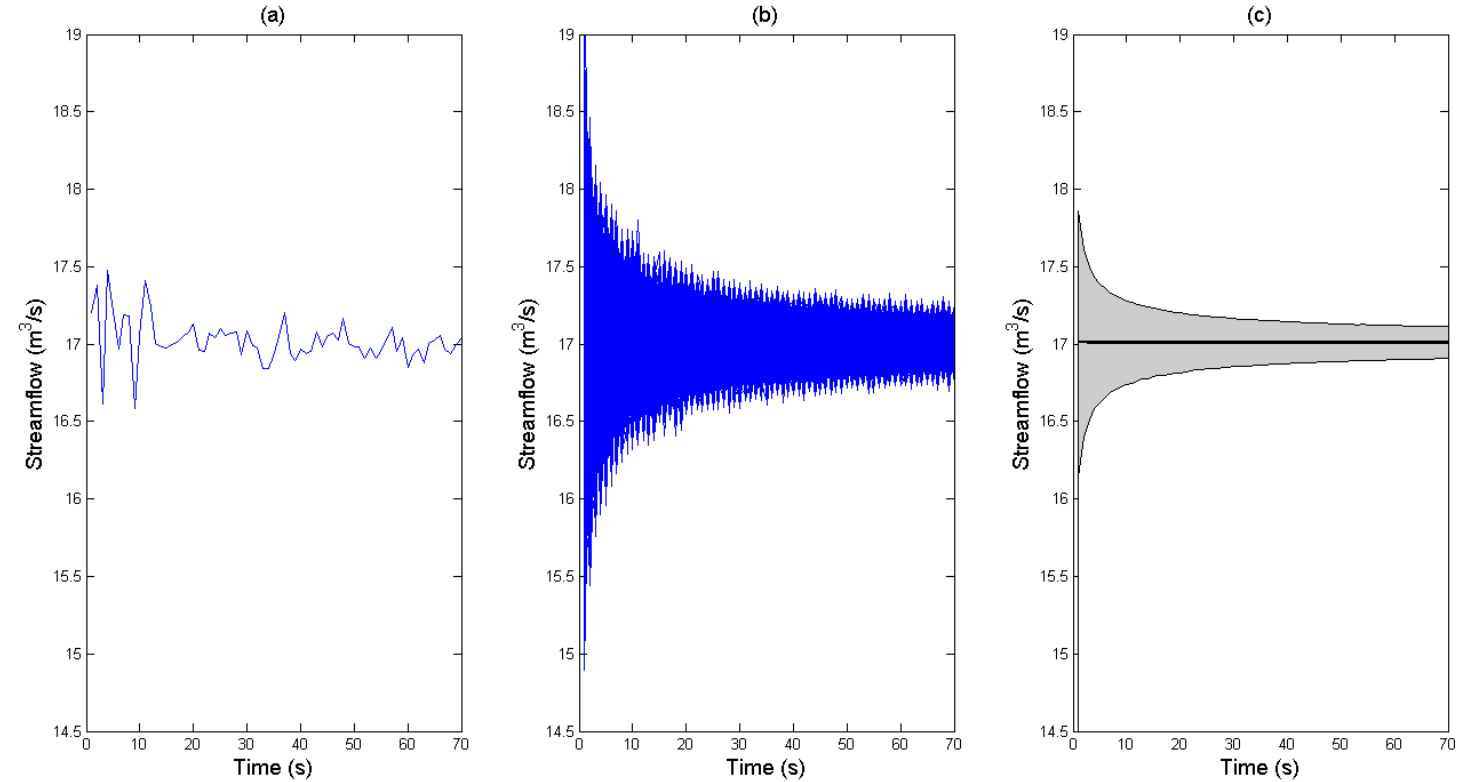

Figure 3. (a) A streamflow calculation simulation for different measurement times, (b) 50,000 streamflow simulations for different measurement times, (c) uncertainty bands for a flow measurement, discarding the $5 \%$ highest and lowest simulations, with the black line representing their average.

A Valeport 801 electromagnetic flow meter was used for the velocity field measurements. This device has a precision of $\pm 0.5 \%$. Electromagnetic meters are suitable for point velocity measurements and have the advantage of having no moving parts, which eliminates uncertainty due to friction and resistance [12]. To analyze the effect of instrument precision on the calculation of the uncertainty bands, an error factor that varied randomly within the precision range of the device (between 0.995 and 1.005, which corresponds to an instrumental error of $\pm 0.5 \%$ ) was used. Each velocity value used in the calculation of the uncertainty bands was multiplied by a randomly chosen error factor with uniform distribution within the precision range. Then, in order to analyze the influence of the instrumental error on the uncertainty bands, the percent change values of the upper and lower uncertainty bands for each gauge were compared. The results for Gauge 1 are shown in Figure 4.

Figure 4 shows that the dispersion does not exhibit trends and its differences are less than $0.004 \%$, which demonstrates that the effect of the precision of the device on the uncertainty calculation is negligible. Therefore, it was not considered in subsequent analyses. 


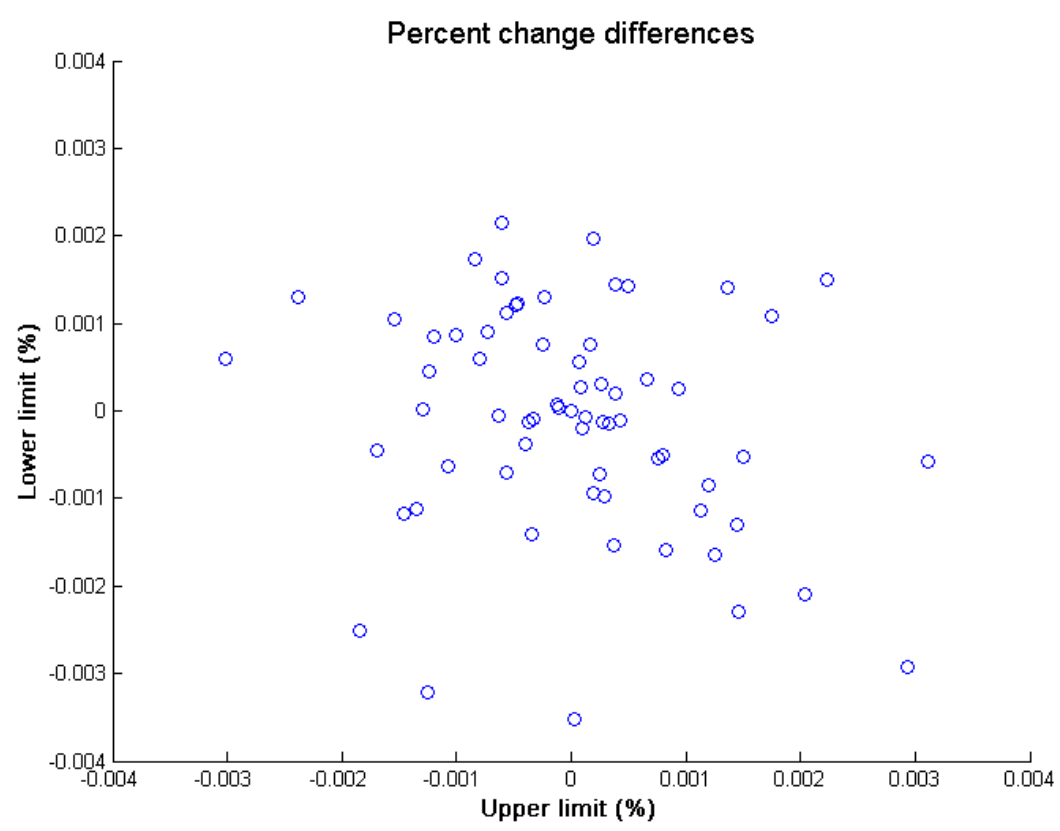

Figure 4. Comparison of percent change of upper and lower uncertainty bands resulting from the inclusion of an instrumental error.

To define the optimal point VMT, two criteria were used in which one is based on the uncertainty bandwidth variation over time and another is based on the stability of the upper and lower slopes of the uncertainty band. The bandwidth was considered the difference between the upper and lower bounds of the band. This width defines the range of the total streamflow results in $\mathrm{m}^{3} / \mathrm{s}$ for the different measurement times. To determine the variation of the uncertainty bandwidth, the percent difference was calculated every second (Equation (1)) where $H_{i}$ is the bandwidth value at a given time $i$.

$$
\text { Percent difference }=\frac{H_{i-1}-H_{i}}{H_{i-1}} \times 100
$$

It was established that percent differences in bandwidth variation from one second to the next of less than $5 \%$ are not significant. Therefore, lower variations were considered a stabilization criterion of the uncertainty bands and a definition criterion of optimal measurement time.

As a complement, the slopes of the upper and lower bounds of each uncertainty band were calculated for every second and their variation was assumed to be negligible for slopes of less than $1 \%$. The uninterrupted satisfaction of both criteria during the measurement time demonstrates the stability in the width and bounds of the band. Therefore, the time at which stability of both criteria began was considered the optimal measurement time. Based on this consideration, continued measurement beyond that time was deemed to contribute neither to a more precise solution nor lower uncertainty.

Lastly, the results of the flow measurements taken in the field, their bands, bounds, and bandwidths were compared and all of the criteria defined for optimal time selection were applied. In addition, the change in uncertainty between different measurement times was analyzed and quantified.

\section{Results}

Uncertainty bands, the width of each and the slopes of their upper and lower bounds were obtained for the eight gauging points. Figure 5 shows, as an example, the results of Gauge 4 . In addition, Figure 5 includes the criteria of bandwidth variation less than $5 \%$ (blue circles in Figure $5 \mathrm{~b}$ ) and slopes of the upper and lower bounds less than 1\% (blue and red circles in Figure $5 c$, respectively). 
Streamflow Uncertainty

(a)

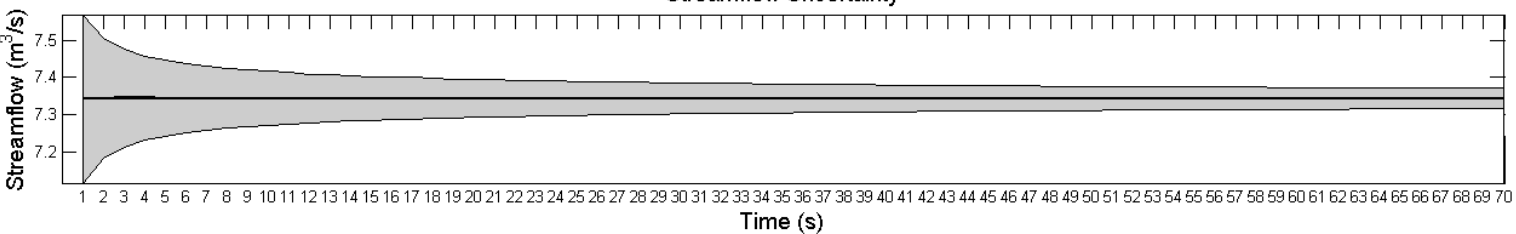

(b)

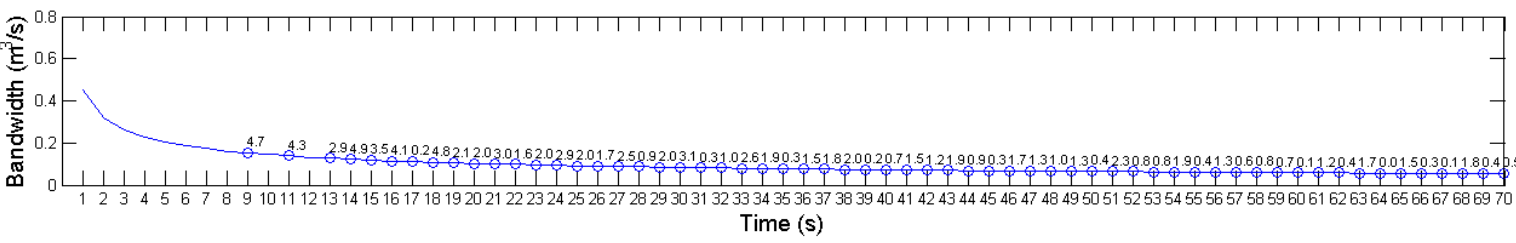

(c)

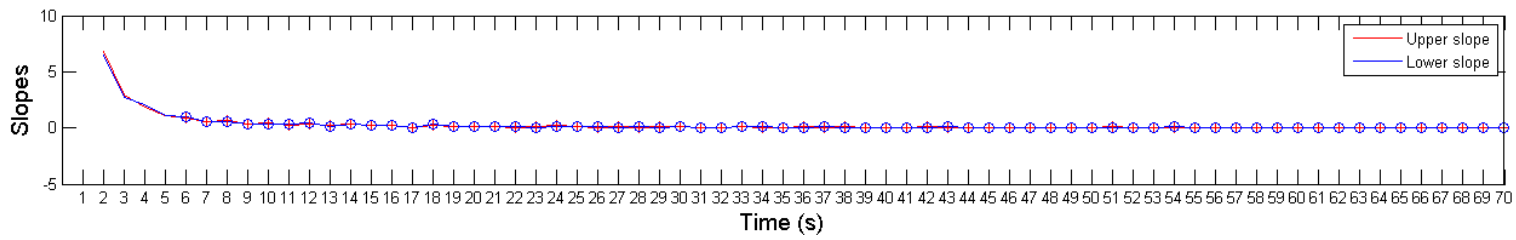

Figure 5. Representation of flow measurement results, (a) uncertainty bands, (b) bandwidths with indicators for the criterion of percent variation less than $5 \%$, (c) upper and low slopes with indicators for the criterion of slopes less than $1 \%$.

Figure 5 shows that the uninterrupted percent change of less than $5 \%$ is established after $13 \mathrm{~s}$. Regarding the criterion of variation of the upper and lower bounds of the uncertainty band, it is observed that the two slopes vary by less than $1 \%$ starting at six seconds. Therefore, for Gauge 4 , the optimal measurement time according to both criteria is $13 \mathrm{~s}$.

Figure 6 shows the results obtained for the eight gauging points, which indicates the time at which the criteria of the slope of less than $1 \%$ (blue circles) and percent change in bandwidth of less than 5\% (green circles) are established. As a comparison, a second stability criterion for bandwidth, calculating the time at which percent change is lower than $2.5 \%$ (red circles), was added. Based on the results shown in Figure 6, an optimal time of $17 \mathrm{~s}$ is obtained using the less than $5 \%$ bandwidth change criterion while $34 \mathrm{~s}$ is the optimal time when a $2.5 \%$ change is considered.

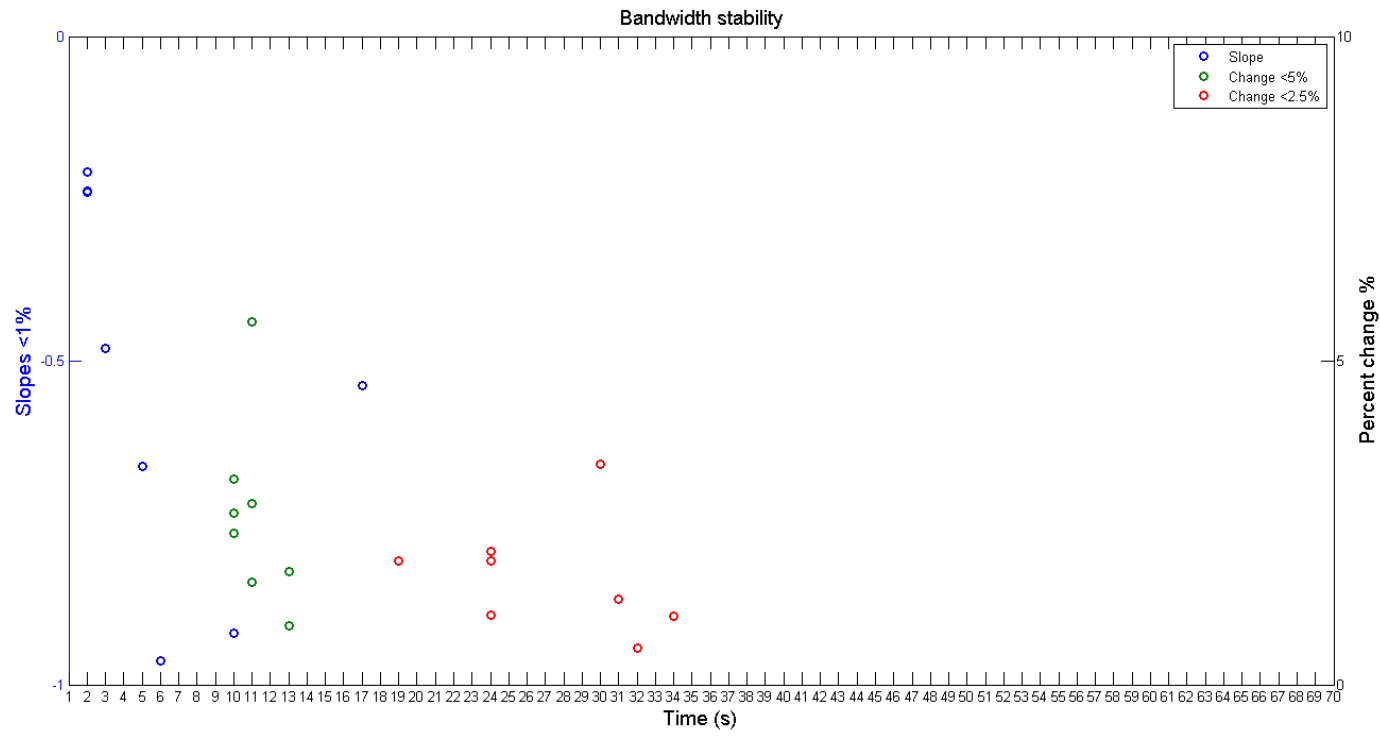

Figure 6. Times at which the different criteria stabilize. 
Given that uncertainty decreases at greater measurement times, the percent benefit of measuring for different times was calculated. To this end, the decrease in the uncertainty band from 17 to $34 \mathrm{~s}$ was calculated and, from 17 to $70 \mathrm{~s}$, the latter is the recommended cut-off time according to USGS [5]. Table 2 shows the obtained results.

Table 2. Percent difference of uncertainty bandwidth for different times.

\begin{tabular}{ccc}
\hline \multirow{2}{*}{ Flow Measurement } & \multicolumn{2}{c}{ Change (\%) from 17 s } \\
\cline { 2 - 3 } & to 34 s & to 70 s \\
\hline 1 & -0.79 & -1.24 \\
2 & -0.46 & -0.78 \\
3 & -0.52 & -0.91 \\
4 & -0.60 & -1.03 \\
5 & -0.37 & -0.64 \\
6 & -1.32 & -2.27 \\
7 & -0.67 & -1.15 \\
8 & -0.24 & -0.40 \\
Mean & -0.61 & -1.05 \\
\hline
\end{tabular}

Table 2 shows that, on average, the uncertainty bands decrease by only $0.61 \%$ and $1.05 \%$ when the VMT increases from $17 \mathrm{~s}$ to 34 and $70 \mathrm{~s}$, respectively. Similarly, it is observed that uncertainty decreases by a maximum of $1.32 \%$ and $2.27 \%$ when measuring for $34 \mathrm{~s}$ and $70 \mathrm{~s}$, respectively. Given that the variation in uncertainty related to measurement time is considerably low, the criterion of percent variation is less than $5 \%$, which represents the stability of the bandwidth curve. This was chosen to define the optimal point VMT. Therefore, according to these criteria, the measurement time at which the uncertainty bands stabilize and their contribution to the quality of the results is no longer significant begins at $17 \mathrm{~s}$, which can be recognized as the optimal point VMT for a flow measurement.

Based on the obtained results, a VMT of $20 \mathrm{~s}$ can be recommended for shallow rivers with characteristics in the range presented in this study following the flow measurement method established by the USGS [5]. Comparing the uncertainty of flow measurements carried out for $20 \mathrm{~s}$ and $70 \mathrm{~s}$, which is the maximum average VMT for a flow measurement point according to USGS [5] regulations. An average reduction in uncertainty of $0.89 \%$ is obtained for the eight gauged sections with a maximum of $1.95 \%$ (obtained for Gauge 6).

Considering the criteria of slopes less than $1 \%$ and percent variation of bandwidth less than $5 \%$, the time of stability is concentrated between 10 and $13 \mathrm{~s}$ with a flow measurement that meets this criterion at $17 \mathrm{~s}$. In addition, the fulfillment of stability conditions considering a percent variation in bandwidth less than $2.5 \%$ for all the flow measurements is found at $34 \mathrm{~s}$.

\section{Conclusions}

Based on an uncertainty analysis of eight flow measurements carried out in shallow rivers with different characteristics in South-central Chile, it was found that the optimal point VMT is $17 \mathrm{~s}$.

It is recommended that point velocity measurements in a gauging be made for a time of $20 \mathrm{~s}$. The benefit of measuring for $70 \mathrm{~s}$, which is the maximum VMT recommended by USGS [5] compared to measuring for $20 \mathrm{~s}$, was calculated. It was found that average uncertainty was reduced by only $0.89 \%$.

With further work, it is expected to increase by both the number of river analyzed to estimate the optimal VMT and the diversity of them by incorporating, for example, deep rivers.

Author Contributions: R.C. and E.M. performed the measurement, calculations, and analyses, and wrote the paper.

Funding: This research was funded by the CIBAS center and by the FONDECYT 11121287 project. 
Acknowledgments: The authors thank: (i) the undergraduate students E.A., H.E., A.S., and S.M. for their contribution in the field surveys, and (ii) the Civil Engineering PhD program of the Universidad Católica de la Santísima Concepción for contributing to this research.

Conflicts of Interest: The authors declare no conflict of interest.

\section{References}

1. Dirección General de Aguas (DGA). Manual Básico para Instrucción de Hidromensores; Ministerio de Obras Públicas: Santiago de, Chile, 1991.

2. U.S. Bureau of Reclamation (USBR). Water Measurement Manual; U.S. Department of the Interior: Washington, WA, USA, 2001.

3. Fernández, G.; Fernández, H.; Meissl, A. Determinación de Incertidumbre de Medición de Caudal Líquido en Cauces; XXVII Congreso Latinoamericano de Hidráulica: Lima, Perú, 2016.

4. U.S. Geological Survey (USGS). Discharge Measurements at Gaging Stations; USGS: Washington, WA, USA, 2010.

5. U.S. Geological Survey (USGS). Measurement and Computation of Streamflow: Measurement of Stage and Discharge; USGS: Washington, WA, USA, 1983.

6. McMillan, H.; Krueger, T.; Freer, J. Benchmarking observational uncertainties for hydrology: Rainfall, river discharge and water quality. Hydrol. Process 2012, 26, 4078-4111. [CrossRef]

7. Westerberg, I.K.; McMillan, H.K. Uncertainty in hydrological signatures. Hydrol. Earth Syst. Sci. 2015, 19, 3951-3968. [CrossRef]

8. United Nations Educational, Scientific and Cultural Organization (UNESCO). Hidrología y Desarrollo de Los Recursos Hídricos en un Medio Ambiente Vulnerable; Programa Hidrológico Internacional: París, Francia, 1996.

9. Coxon, G.; Freer, J.; Westerberg, I.K.; Wagener, T.; Woods, R.; Smith, P.J. A novel framework for discharge uncertainty quantification applied to 500 UK gauging stations. Water Resour. Res. 2015, 51, 5531-5546. [CrossRef] [PubMed]

10. Saldías, L. Automatización de Aforos y Reportes de Terreno en Ingeniería Hidráulica. Civil Engineering Thesis, Universidad Católica de la Santísima Concepción, Concepción, Chile, May 2016.

11. Helmbrecht, J.; López, J.; Villegas, J. Cálculo de Incertidumbres en la Medida de Caudales en Ríos y Canales: Herramientas y Aplicaciones Prácticas Innovadoras. Ingeniería del Agua. 2004. Available online: http:/ / www.ingenieriadelagua.com/2004/jia/jia2011/pdf/p588.pdf (accessed on 28 July 2018).

12. International Organization for Standardization (ISO 748-2007). Hidrometría. In Medida del Caudal de Líquidos en Canales Abiertos Utilizando Medidores de Caudal o Flotadores; AENOR: Madrid, España, 2007.

13. Beven, K.; Binley, A. The future of distributed models: Model calibration and uncertainty prediction. Hydrol. Process 1992, 6, 279-298. [CrossRef]

14. Hornberger, G.M.; Spear, R. An approach to the preliminary analysis of environmental systems. J. Environ. Manag. 1981, 12, 7-18.

15. Spear, R.C.; Grieb, T.M.; Shang, N. Parameter uncertainty and interaction in complex environmental models. Water Resour. Res. 1994, 30, 3159-3169. [CrossRef]

16. Paredes, P. Sobre el rol de la Incertidumbre Hidrológica en la Modelación de Inundaciones a Gran Escala: Río Usumacinta, Tabasco. Master's Thesis, Universidad Nacional Autónoma de México, México, 2013.

17. Camacho, L.; Cantor, M. Calibración y análisis de la capacidad predictiva de modelos de transporte de solutos en un río de montaña colombiano. Avances Recursos Hidráulicos 2006, 14, 39-52.

18. Shen, Z.Y.; Chen, L.; Chen, T. Analysis of parameter uncertainty in hydrological and sediment modeling using GLUE method: A case study of SWAT model applied to Three Gorges Reservoir Region, China. Hydrol. Earth Syst. Sci. 2012, 16, 121-132. [CrossRef]

19. Vargas-Luna, A.; Monroy, J. Estudio del comportamiento de modelos hidrológicos bajo un análisis de sensibilidad e incertidumbre. Ingeniería de Recursos Naturales y del Ambiente 2011, 10, 65-77. 